IOS Press

\title{
Review
}

\section{Cerebrospinal Fluid Biomarkers for Alzheimer's Disease: A View of the Regulatory Science Qualification Landscape from the Coalition Against Major Diseases CSF Biomarker Team}

Stephen P. Arnerića,*, Richard Batrla-Utermann ${ }^{\mathrm{b}}$, Laurel Beckett ${ }^{\mathrm{c}}$, Tobias Bittner ${ }^{\mathrm{b}}$, Kaj Blennow $^{\mathrm{d}}$, Leslie Carter ${ }^{\mathrm{e}}$, Robert Dean ${ }^{\mathrm{f}}$, Sebastiaan Engelborghs ${ }^{\mathrm{g}}$, Just Genius ${ }^{\mathrm{e}}$, Mark Forrest Gordon ${ }^{\mathrm{h}}$, Janice Hitchcock ${ }^{\mathrm{f}}$, June Kaplow ${ }^{\mathrm{i}}$, Johan Luthman ${ }^{\mathrm{i}}$, Richard Meibach ${ }^{\mathrm{j}}$, David Raunig ${ }^{\mathrm{k}}$, Klaus Romero ${ }^{a}$, Mahesh N. Samtani ${ }^{1}$, Mary Savage ${ }^{\mathrm{m}}$, Leslie Shaw ${ }^{\mathrm{n}}$, Diane Stephenson ${ }^{\mathrm{a}}$, Robert M. Umek ${ }^{\mathrm{o}}$, Hugo Vanderstichele ${ }^{\mathrm{p}}$, Brian Willis ${ }^{\mathrm{f}}$ and Susan Yule ${ }^{\mathrm{q}}$

${ }^{a}$ Critical Path Institute, Coalition Against Major Diseases, Tucson, AZ, USA

${ }^{\mathrm{b}}$ Roche Diagnostics, Basel, Switzerland

${ }^{\mathrm{c}}$ University of California, Davis, CA, USA

${ }^{\mathrm{d}}$ Clinical Neurochemistry Lab, Institute of Neuroscience and Physiology, The Sahlgrenska Academy at University of Gothenburg, Sahlgrenska University Hospital, Mölndal, Sweden

eAbbVie, Abbott Park, IL, USA

${ }^{\mathrm{f}}$ Eli Lilly and Company, Indianapolis, IN, USA

${ }^{\mathrm{g}}$ Reference Center for Biological Markers of Dementia (BIODEM), University of Antwerp, Antwerp, Belgium

${ }^{\mathrm{h}}$ Boehringer Ingelheim Pharmaceuticals, Inc., Ridgefield, CT, USA

${ }^{\mathrm{i}}$ Eisai, Woodcliff Lake, NJ, USA

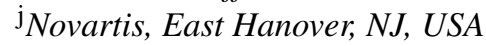

${ }^{\mathrm{k}}$ Icon, Warrington, PA, USA

${ }^{1}$ Janssen R\&D, Raritan, NJ, USA

${ }^{\mathrm{m}}$ Merck, Rahway, NJ, USA

${ }^{\mathrm{n}}$ University of Pennsylvania, Philadelphia, PA, USA

${ }^{\circ}$ Meso Scale Diagnostics, LLC, Rockville, MD, USA

p Biomarkable, Gent, Belgium

${ }^{\mathrm{q}}$ Genentech/Roche, San Francisco, CA, USA 


\begin{abstract}
Alzheimer's disease (AD) drug development is burdened with the current requirement to conduct large, lengthy, and costly trials to overcome uncertainty in patient progression and effect size on treatment outcome measures. There is an urgent need for the discovery, development, and implementation of novel, objectively measured biomarkers for AD that would aid selection of the appropriate subpopulation of patients in clinical trials, and presumably, improve the likelihood of successfully evaluating innovative treatment options. Amyloid deposition and tau in the brain, which are most commonly assessed either in cerebrospinal fluid (CSF) or by molecular imaging, are consistently and widely accepted. Nonetheless, a clear gap still exists in the accurate identification of subjects that truly have the hallmarks of AD. The Coalition Against Major Diseases (CAMD), one of 12 consortia of the Critical Path Institute (C-Path), aims to streamline drug development for AD and related dementias by advancing regulatory approved drug development tools for clinical trials through precompetitive data sharing and adoption of consensus clinical data standards. This report focuses on the regulatory process for biomarker qualification, briefly comments on how it contrasts with approval or clearance of companion diagnostics, details the qualifications currently available to the field of $\mathrm{AD}$, and highlights the current challenges facing the landscape of CSF biomarkers qualified as hallmarks of AD. Finally, it recommends actions to accelerate regulatory qualification of CSF biomarkers that would, in turn, improve the efficiency of $\mathrm{AD}$ therapeutic development.
\end{abstract}

Keywords: Alzheimer's disease, biomarker qualification, cerebrospinal fluid biomarkers, Coalition Against Major Diseases

\section{BACKGROUND}

Biomarker development and subsequent integration into drug development is critical to accelerating effective treatments for chronic diseases of high unmet need. Precompetitive consortia serve as catalysts to advance biomarker development for use in clinical trials. The Food and Drug Administration (FDA) has two distinct regulatory paths to achieve regulatory acceptance of biomarkers for use in clinical trials: 1) biomarker acceptance through the drug approval process, and 2) the Biomarker Qualification Program. Both pathways can lead to the successful implementation of a biomarker in a clinical trial under a specifically supported "fitness for purpose". The European Medicines Agency (EMA) has also developed similar regulatory pathways for biomarker integration in clinical trials via the Qualification of Novel Methodologies for Drug Development process, in addition to obtaining biomarker acceptance via use in clinical trials.

The first path, the drug approval process, advances the use of a biomarker(s) during development of a novel therapeutic candidate; the biomarker review occurs during the formal review process of the sponsor's Investigational New Drug (IND), New Drug Application (NDA), or Biologic License Application (BLA), or through the equivalent regulatory processes within the EMA. The second path, the Biomarker Qualification Program, developed by the Center for Drug Evaluation and Research (CDER) $[1,2]$, has been implemented by the FDA, with the subsequent introduction of a similar pathway, the Qualification of Novel Methodologies for Drug Development process, within the EMA [3].
Biomarker qualification is defined as a conclusion that within a carefully and specifically stated context of use (COU), the biomarker has been demonstrated to reliably support a specified manner of interpretation and application in drug development [2]. The COU is a comprehensive statement that fully and clearly describes the manner and purpose of use for the biomarker in drug development. Defining a COU is the cornerstone of the qualification discussion as it determines the level of evidence required to support qualification. This qualification can range from that of diagnostic biomarkers used to identify individuals with the disease or defines a subset of the disease, to prognostic biomarkers used to determine the likelihood of a clinical event, disease recurrence, or progression [2], and to predictive biomarkers that are used as enrichment biomarkers, that are reinforcing trials entry criteria to identify individuals who are more likely to respond to a drug under investigation to a monitoring biomarker that can serve as reflection of drug treatment mechanism of action or treatment outcome, that may eventually become a surrogate biomarker for clinical outcome measures [4]. The level of evidence needed for qualification depends on the category of biomarker (e.g., prognostic, predictive, monitoring, etc.) and the COU (Fig. 1). Qualification of biomarkers can be a resource intensive process and collaborative efforts by groups such as consortia enable the sharing of cost and risk required to obtain the varying levels of evidence needed to support the regulatory endorsement of biomarkers for widespread use.

In 2015, the FDA-NIH Joint Leadership Council identified the harmonization of terms used in translational science and medical product development 


\section{Biomarker Qualification is Dependent Upon Context of Use}

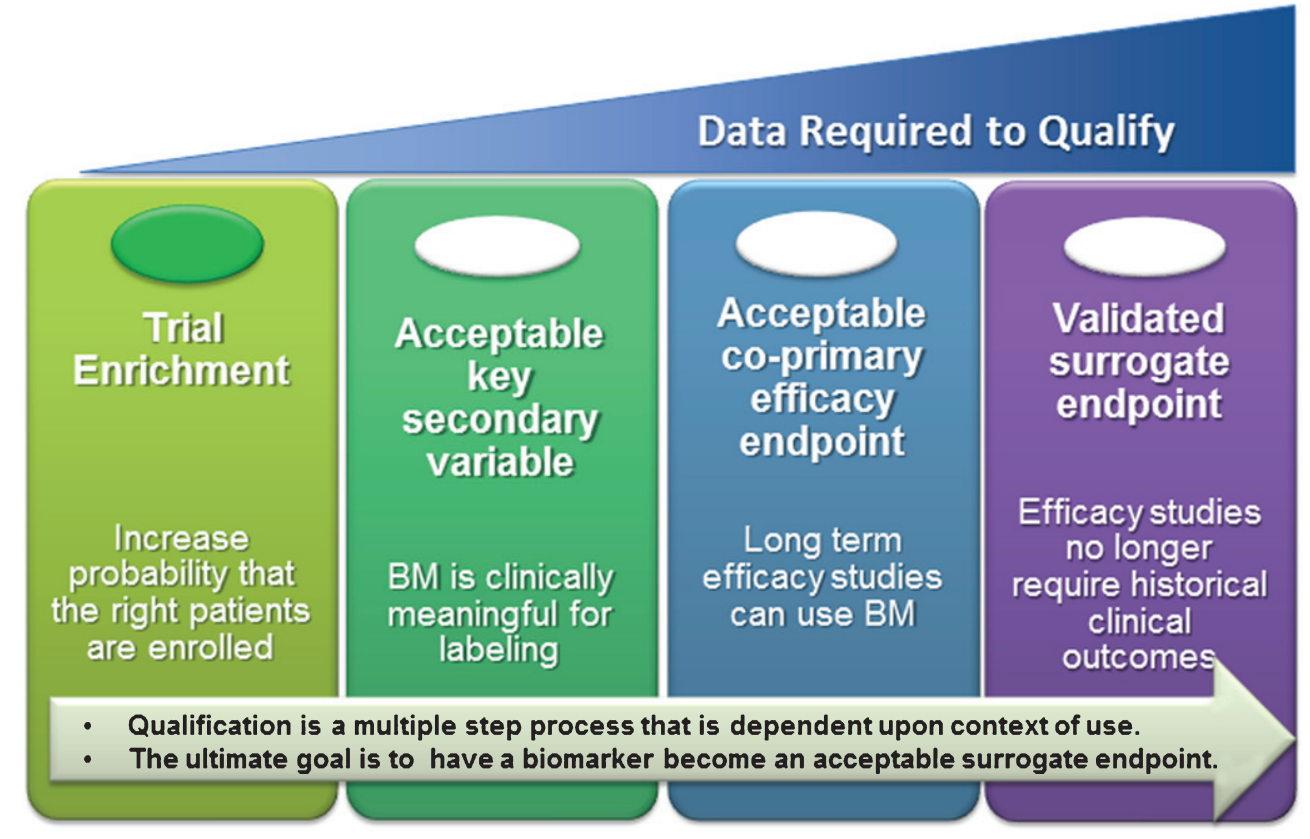

Fig. 1. Qualification of clinical biomarkers, regardless of target patient population, is focused on acquiring sufficient patient level anonymized data to support a given "context-of- use" (COU) for clinical trial decision making. The greater the impact this clinical decision (i.e., COU) has on the patient, the greater the evidence that will be required to support a qualification recommendation by a regulatory agency. The focus of CAMD's work is to provide sufficient evidence for the use of CSF biomarkers for trial enrichment in the pre-dementia stage of AD. Note: At the time of this publication, no clinical biomarker has been qualified as a validated surrogate endpoint for any neurological indication.

as a priority need, with a focus on terms related to study endpoints and biomarkers. With the goals of improving communication, aligning expectations, and improving scientific understanding, the two agencies developed the BEST (Biomarkers, EndpointS, and other Tools) Resource [5]. The first phase of BEST comprises a glossary that clarifies important definitions and describes some of the hierarchical relationships, connections, and dependencies among the terms it contains with the aim to capture distinctions between biomarkers and clinical assessments. It is a meant to represent a living resource that describes their evolving roles in biomedical research, clinical practice, regulatory science advance of drug development tools (DDTs), and medical product development. The EMA has not issued a biomarker glossary, however several guidelines, including the novel draft guidelines on the clinical investigation of medicines for the treatment of Alzheimer's disease (AD) and other dementias, recognize enrichment biomarkers and their critical role in defining trial populations [6].

One example of a collaborative effort to develop biomarkers for regulatory acceptance is from the
Coalition Against Major Diseases (CAMD), one of 12 consortia of the Critical Path Institute (C-Path), whose aim is to streamline drug development for $\mathrm{AD}$ and related dementias by advancing regulatory DDTs for clinical trials [7, 8]. C-Path was established in 2005 in response to the FDA's Critical Path Initiative [9]. C-Path serves as a catalyst in the development of new approaches to advance medical innovation and regulatory science by leading teams that share data, knowledge, and expertise to produce sound, consensus-based science [10,11]. CAMD has achieved success in gaining regulatory endorsement from the EMA for the use of low baseline hippocampal volume as assessed by volumetric magnetic resonance imaging (vMRI) as prognostic biomarker for clinical trial enrichment for pre-dementia AD trials $[12,13]$ and regulatory endorsement by both the EMA and FDA of a fit-for-purpose clinical trial simulation model of mild-to-moderate AD to aid in clinical trial design [14].

Core to achieving CAMD's mission is precompetitive data sharing and adoption of consensus clinical data standards (Neville et al., 2016, manuscript in preparation) [15]. CAMD works to achieve 
regulatory qualification for biomarkers that enrich clinical trial populations targeting early clinical stages of disease. One of CAMD's efforts include an AD CSF Qualification project that engages a team consisting of pharmaceutical and diagnostics industry experts, academic opinion leaders, nonprofit organizations, and regulatory agency representatives. The goal of this team is to, with the guidance of the FDA, qualify the use of CSF analytes $A \beta_{1-42}$, total tau (t-tau), and/or phosphorylated tau (p-tau), as biomarkers for enrichment in pre-dementia AD clinical trials [16]. The aim of the CAMD CSF project is thus to aim for obtaining regulatory acceptance of CSF measures of $A \beta_{1-42}$, t-tau, and/or p-tau as prognostic biomarkers within the $\mathrm{COU}$ as trial enrichment biomarkers that are identifying subjects which have a much higher likelihood to have AD pathology and consequently are expected to progressively decline clinically, making them suitable as trial subjects in drug development programs addressing $\mathrm{AD}$ pathophysiology. To date, the FDA has issued a letter of support to CAMD encouraging the further use and study of CSF analytes as exploratory prognostic biomarkers for enrichment in clinical trials targeting the predementia stage of the disease. Other precompetitive consortia play a key role in advancing CSF biomarkers for use in drug development, including Alzheimer's Disease Imaging Initiative Private Partner Scientific Board (ADNI - PPSB) [17], the International Federation of Clinical Chemistry Working Group for CSF proteins (IFCC-WG CSF) [18], and the Alzheimer's Association, Global Biomarker Standardization Consortium [19]. Continued alliances across consortia will augment progress by enhancing and expanding initiatives including the establishment of global biorepositories, improved assay analytical performance metrics and development of reference standards for distinct candidate analytes. In addition to the qualification of the candidate biomarkers under review, there is a critical need to advance novel biomarkers and disease progression models for regulatory endorsement across all stages of disease progression (pre-symptomatic to end-stage disease). Continued building of infrastructure to support novel biomarker validation and regulatory qualification will reduce the uncertainty of drug development for $\mathrm{AD}$, a devastating disease in urgent need of both effective therapies and improved ways to assess disease progression [20].

This manuscript describes the regulatory experiences, learnings, and recommendations of the CAMD AD CSF biomarker team to qualify CSF biomarkers,
$A \beta_{1-42}$, t-tau, and/or $p$-tau for the specific application of clinical trial enrichment in predementia $A D$ registration trials and also highlights some of the more pertinent recent publications on the topic.

\section{UNMET NEED FOR BIOMARKERS IN AD}

For $\mathrm{AD}$, the need is especially great since evaluation of drug response using current clinical measures requires very large, lengthy, and costly trials. The high failure rate of $\mathrm{AD}$ drug development $[22,23]$ is further incentive to employ biomarkers successfully in clinical trials. Effort to implement biomarkers for subject selection were intensified when it was found that up to one-fourth of subjects enrolled in two very large clinical anti-amyloid therapy trials targeting subjects at the mild/moderate stage of AD lacked evidence of amyloid-related pathology as evaluated by positron emission tomography (PET) [21, 23]. This illustrates that a significant proportion of subjects enrolled in clinical trials for AD therapy may show limited or no benefit from otherwise effective amyloid targeted treatments if AD-relevant biomarkers were absent, hence, diluting the relevant treatment population and ability to estimate benefit. Nonetheless, multimodal imaging assessment of different types of neuropathology remain a high priority as the method of choice for a reliable and specific detection and quantification of $\mathrm{AD}$ neuropathology in vivo, and, thus, many continue to pursue this as the approach of choice for prevention strategies [24].

Clinicopathologic investigations indicate that there is a clear gap in accurate identification of subjects that truly have the hallmarks of AD. Notably a recent report documented that more than one-third of $A P O E \& 4$ non-carriers, with the primary clinical diagnosis of mild to moderate AD dementia, had minimal $A \beta$ plaque accumulation in the cerebral cortex based on clinicopathological findings from the National Alzheimer Coordinating Center's (NACC) Uniform Data Set [25]. The NACC is responsible for developing and maintaining a database of participant information collected from the 29 Alzheimer's Disease Centers (ADCs) funded by the National Institute on Aging (NIA). The ADC Clinical Task Force defined and created a standardized clinical data set, called the Uniform Data Set (UDS). The goal of the UDS is to provide ADC researchers a standard set of assessment procedures, collected longitudinally, to better characterize ADC participants with mild Alzheimer disease and mild cognitive impair- 
ment in comparison with non-demented controls. It was also observed that approximately half of these participants, with a primary clinical diagnosis of mild to moderate Alzheimer dementia and minimal $A \beta$ plaque accumulation, also lacked evidence of neurofibrillary degeneration upon postmortem examination. Such striking findings highlight the importance of accurate identification of subjects for clinical trials.

The confidence in diagnostic accuracy as assessed by clinical features alone is even more challenging at earlier stages of the disease. Therefore, clinical trials of $\mathrm{AD}$ therapeutics targeting early stages of the disease are currently employing biomarkers for subject inclusion and patient stratification according to the diagnostic criteria collectively endorsed by the consensus of experts in the field [26, 27]. Evidence from ADNI-1 suggests that there is a temporal relationship of pathologic events in AD, CSF biomarkers, and progression to $\mathrm{AD}[28,29]$. Although the latter study shows there is value in using CSF biomarkers, when compared to the sensitivity of the AD signature MRI biomarker of cortical thickness, the effect was inferior.

While regulatory agencies have acknowledged the importance of biomarkers in $\mathrm{AD}$ drug development [30] and clinical trial enrichment [31-33], the greatest impediment to qualifying a CSF biomarker for $\mathrm{AD}$ trial enrichment by regulatory agencies has been gaining access to patient-level, anonymized data to support the qualification process. The reasons underlying this impediment will be discussed in greater detail in the following sections.

\section{THE CONSENSUS LANDSCAPE OF CSF BIOMARKERS FOR AD}

Despite decades of research that led to the identification of potential biomarkers with links to AD pathophysiology (plaques, tangles, neuronal and synaptic degeneration and loss, oxidative stress, inflammation), only a few biomarkers remain consistently and widely accepted [34]. These include biomarkers linked to amyloid deposition and neurodegeneration in the brain, which are most commonly assessed either in CSF or by molecular neuroimaging. The initial identification and early understanding of the potential utility of these biomarkers has been enabled by Alzheimer's Disease Neuroimaging Initiative (ADNI). ADNI has exceeded its initial goals of $\mathrm{AD}$ biomarker standardization and characterization of disease progression and serves as a key example of the role of precompetitive collaborations in transforming our understanding of $\mathrm{AD}$ and incentivizing drug development [35].

Compared to amyloid PET, CSF biomarkers offer the potential of measuring, multiple analytes in the same sample, reflecting distinctive pathologic hallmarks. Like volumetric measures of brain structure that reflect a spectrum of interrelated neurobiochemical process changes, assessing multiple analytes may provide a more reflective picture of the ongoing dynamic changes in accessible biomarkers. CSF, by virtue of its close association with brain interstitial fluid, is a fluid matrix well suited for assessing the biochemical processes occurring in and around the cells of the brain. In addition, biochemical analytes measured in CSF are often reflective of pathogenic processes in the brain [36].

AD biomarkers that have been extensively studied include $A \beta_{1-42}$, t-tau, and p-tau. $A \beta_{1-42}$ is the most abundant form of $A \beta$ found in amyloid plaques [37]. Moreover, the reduced concentration of $A \beta_{1-42}$ in CSF of individuals with $A D$ pathology is presumed to reflect aggregation of $A \beta_{1-42}$ in brain parenchyma [38-40]. Further reduction in CSF A $\beta$ is known to occur longitudinally as fibrillar $A \beta$ is deposited as plaques in the brain [41, 42].

An increase in CSF t-tau levels likely reflects an index of neurodegeneration and have been shown to correlate with the amount of neurofibrillary tangles in the brain [41]. Importantly, a multitude of distinct studies have shown that individuals with mild cognitive impairment (MCI) who progressed to AD dementia have decreased levels of CSF $A \beta_{1-42}$ together with increased levels of CSF t-tau and ptau [43-45]. However, it should be recognized that although elevated levels of t-tau reflect an ongoing neurodegenerative process, the localization within different brain circuits can vary widely [46] which is consistent with variance in the constellation of symptoms expressed across different neurodegenerative disorders.

A systematic review of studies employing these CSF biomarkers confirmed that low $\mathrm{A} \beta_{1-42}$ combined with high t-tau or p-tau represent a sensitive and specific biomarker signature of disease progression from MCI to AD dementia [47, 48]. This CSF biomarker signature has been confirmed by multiple investigators across numerous independent cohorts despite the use of different assays and cut-points. A recent meta-analysis aimed at identifying the risk factors for predicting the progression from MCI to 
AD inventoried over 14,000 participants across 16 countries and reported that the ratio of CSF tau and $A \beta_{1-42}$ was one of the most significant predictors of disease progression [49].

The use of CSF analytes $A \beta_{1-42}$, t-tau and p-tau for selecting clinical trial subjects has been explored as a way to ensure that subjects enrolled in the trial have a high likelihood of showing disease progression in clinical trials of prodromal AD subjects [50]. By measuring CSF analytes at baseline, subjects who are unlikely to progress or decline in cognition and function can be excluded from the trial. In addition, by using specific cut-off scores for the relevant analyte(s), subjects who are likely to measurably decline during the study period could potentially be identified, thus reducing the number of subjects required to achieve the appropriate statistical power.

Significant gaps exist in successfully implementing CSF biomarkers in global clinical trials. At present, there is no consensus on threshold/cut-off values for the CSF AD analytes and absolute levels of analytes vary substantially between laboratories even when employing a single assay platform [51]. In addition, there is also no consensus on the use of single biomarker or a combination of biomarkers. Such issues are important to address for successful implementation of AD CSF biomarkers in multisite clinical trials. For example, the use of CSF biomarkers has been hampered by the lack of standardization between values generated by different immunoassay formats, the assay lot-to-lot variability, the lack of awareness of all variables that can affect the outcome of a test for one or more analytes, and differences in critical assay reagents. Standardization of CSF biomarker analysis, a clear unmet need, is underway with global initiatives in both EU and US $[19,52,53]$ in order to augment progress and success in multicenter trials. Substantial progress has been made by the International Federation of Clinical Chemistry CSF Working group (IFCC WG-CSF) [54] to provide a reference measurement procedure (RMP) and certified reference material (CRM) for CSF $A \beta_{1-42}$. A CRM, i.e., a universally accepted reference material such as CSF aliquots with exact levels set using the RMP, which can be distributed to kit vendors and large laboratories for harmonization of levels between assay formats and between batches, has been recently approved for $\mathrm{A} \beta_{1-42}[55,56]$ but still requires further development for other CSF analytes. Advancement of mass spectrometric-based methods of amyloid protein will enable both accuracy and precision in the future
[57-61]. Two RMPs for the quantification of CSF $\mathrm{A} \beta_{1-42}$ based on LC-MS/MS have been accepted and listed by the Joint Committee for Traceability in Laboratory Medicine (JCTLM) as RMPs (no. C11RMP9 and C12RMP1). Such developments are essential for multisite global implementation of CSF biomarkers [62].

Increasing focus is being given to identify which group of cognitively normal individuals shows the greatest cognitive decline over time based on their CSF biomarker profile [63]. This study concludes that clinical trials enrolling cognitively normal individuals should selectively recruit participants with abnormal levels of both amyloid and tau (i.e., stage 2) because this group would be more likely to show cognitive decline over time. While this clearly identifies the individuals most likely to progress, it raises a question of critical importance. Is this fast progressing population of patients most likely to be effectively treated with preventive therapies, or is it these patients that are least likely to show improvement?

Finally, there is emerging data to suggest that what is being learned from CSF biomarkers in $\mathrm{AD}$ may share common biochemical themes with CSF biomarkers from other neurodegenerative diseases. There are increasing reports that the profiles for tau in $\mathrm{CSF}$ of patients with $\mathrm{AD}$, progressive supranuclear palsy, and dementia with Lewy bodies is elevated, but with unique patterns [64]. Also, in Parkinson's disease (PD), which is known to have a high incidence of dementia, emerging data suggests that, a fivemarker subset panel employed in a classifier trained to recognize AD CSF analytes (t-tau, $\mathrm{p}$-tau, $\mathrm{A} \beta_{1-42}$ ), $A P O E$ genotype, and SPARE-AD imaging score, also discriminated with $80 \%$ accuracy, cognitively normal PD patients versus PD patients with dementia (PDD) [65]. The authors concluded that: "Thus, an AD-derived biomarker signature may identify PDD patients with moderately high accuracy, suggesting mechanisms shared with AD in some PDD patients. Based on five measures readily obtained during life, this $\mathrm{AD}$-derived signature may prove useful in identifying PDD patients most likely to respond to AD-based crossover therapies." Conceivably, future modeling work combining qualified CSF biomarkers, imaging biomarkers, and other types of functional measures will improve both the sensitivity and specificity to predict disease progression, and perhaps, treatment outcomes. It will be interesting to see whether similar "biomarker fingerprints" of dementia are revealed in other neurodegenerative diseases. 


\section{COMPARISON OF BIOMARKER ACCEPTANCE PATHS AND THEIR USE IN DRUG DEVELOPMENT}

In the context of drug development, biomarkers can be considered to be DDTs. DDT qualifications have been adopted by global regulatory agencies in addition to FDA, including the EMA and Japan's Pharmaceuticals and Medical Device Agency (PMDA). These regulatory pathways provide a framework to evaluate and adopt new tools into regulatory decision making in drug development, increasing the efficiency for achieving consensus science around the appropriate $\mathrm{COU}$ for a new tool in a drug development program. This section will address the similarities and differences between the acceptance of a biomarker as a DDT for a specific therapeutic agent, and the qualification of a biomarker as a DDT across multiple therapeutic interventions (Fig. 2).

The regulatory requirements, evidentiary standards, and performance requirements needed to obtain an Investigational Device Exemption application (IDE) to study an investigational medical device or an In Vitro Diagnostic (IVD) approval from FDA are quite distinct from those required to achieve regulatory agency biomarker qualification [66]. At present, there is confusion by many stakeholders regarding the regulatory implications of an IVD approval versus a qualified biomarker. Biomarker qualification pertains to an application of a reliable measurement method/biomarker for a specific context of use in drug development; critically, it is conceptually independent of a specific test or assay. Approval of a biomarker as a stand-alone diagnostic or IVD pertains to a defined assay for clinical use (stand-alone diagnostic) or for use as a companion with a therapeutic product with a defined mechanism of action (target-dependent "companion diagnostic"). Thus, biomarker qualification has broad applicability to benefit the entire field, while IVD approval applies to a specific diagnostic test, assay, or device. Both regulatory paths are of value and these biomarkers paths can be advanced in parallel.

Regulatory agencies have recommended biomarker qualification as a mechanism to integrate the use of biomarkers into drug development programs

\section{Biomarker Acceptance Pathway Considerations}

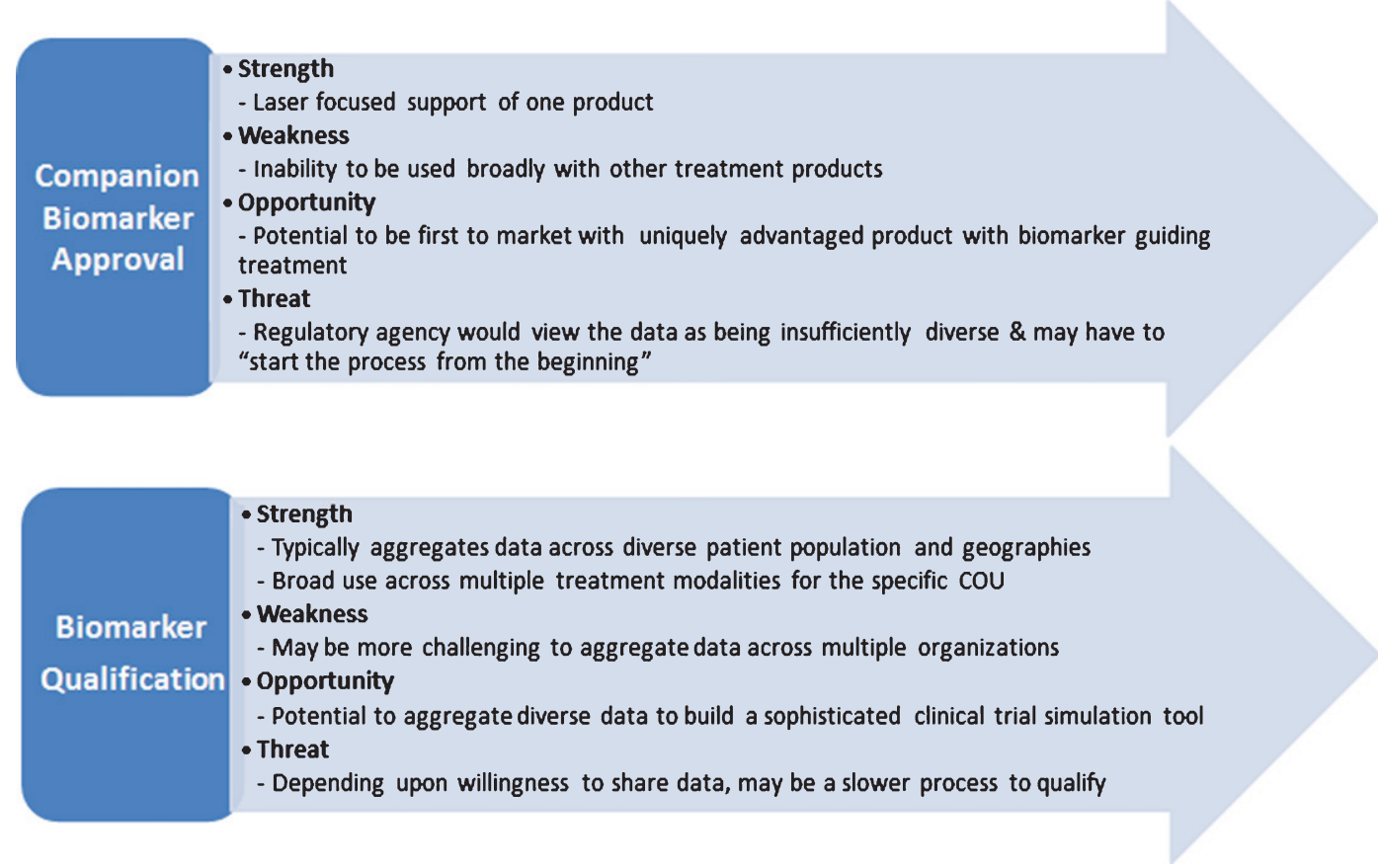

Fig. 2. There are two independent biomarker acceptance pathways through which biomarkers can be integrated into drug development for a specific COU. The first is typically sponsored by a single company, and is focused on delivering a companion diagnostic assay that supports a single therapeutic product. The second is typically done collectively by a consortium that provides a diverse range of clinical data across multiple studies to support a specific COU that would have applicability across multiple treatment modalities. This figure summarizes the high-level considerations of each pathway. 
and improve the efficiency and safety of clinical trials testing novel therapeutics [2, 4]. In its guidance for qualification of DDTs [67], the FDA recognized the challenges of achieving biomarker qualification, and therefore encouraged individuals or companies to collaborate through consortia that foster sharing of precompetitive data and use of data standards [68]. Such efforts distribute the cost and risk of qualification among multiple stakeholders and enable the FDA to perform a single evaluation of a biomarker proposal, as opposed to multiple evaluations of different submissions that might have limited data, when evaluated independently. Importantly, precompetitive efforts within consortia can offer the advantage of larger and conceivably more diverse datasets across ethnic and geographic backgrounds in support of the qualification application.

All entities (e.g., academic, industry, patient groups, and foundations) involved in driving biomarker research for $\mathrm{AD}$ agree that finding a validated biomarker for a specific COU would be transformational for advancing the efforts to find innovative treatments for this devastating disease. Unfortunately, for the patients and their families, a competitive drive has motivated some entities not to share incredibly valuable data with the scientific community, and these entities have approached the regulatory agencies individually in the hopes of having a competitive advantage for their therapeutic product. In addition, informed consent documents often do not allow the distribution of anonymized data to consortia for the future purposes of biomarker qualification. Going forward, organizations participating in consortia efforts to qualify AD biomarkers should provide within informed consent documents clauses to enable patients to share their anonymized data to benefit $\mathrm{AD}$ biomarker qualification.
Notably, Lavezzari and Womack point out there are differences in the trends between therapeutic areas and how biomarker qualification has been focused [69]. Unfortunately, neurology lags behind other therapeutics areas such as oncology in terms of biomarker qualification.

The FDA and EMA have somewhat different policies and procedures for qualifying biomarkers as DDTs (Table 1). Most of these differences relate to the distinctively unique regulatory infrastructures and policies across global regulatory agencies. In the European Union, the EMA Committee for Medicinal Products for Human Use (CHMP) may provide either qualification advice or a qualification opinion, as outlined in a guidance published in 2009, and updated in 2012 and 2014 [3]. The FDA focuses keenly on measurement science and standardization as a critical component of the biomarker qualification and review. Similarly, the EMA stated in their CSF biomarker qualification opinion issued in 2011 [70] (see below), "Collection, procedures and measurements of all CSF samples should be done in accordance with Good Laboratory Practices and the specific International standards for these measurements." In the AD biomarkers that achieved qualification opinions with the EMA, some attention to biomarker standardization is noted, yet much of the decisions are left to the sponsors, leaving the field in many cases without absolute standards to rely upon.

With both agencies, the regulatory implications for qualification require a higher level of supportive evidence as compared to the use of a biomarker to support an individual drug submission and regulatory approval. On the other hand, qualification has broad utility across multiple therapeutic candidates independent of the precise mechanism of action of the drug. Qualification of a particular biomarker

Table 1

Key similarities and differences between the FDA and EMA for biomarker qualification

\begin{tabular}{|c|c|c|}
\hline Consideration & FDA & EMA \\
\hline Fees & None & Fees charged \\
\hline Review Timing & $\begin{array}{l}\text { Review not under PDUFA guidelines; no } \\
\text { timelines imposed; internal experts }\end{array}$ & $\begin{array}{l}\text { Accelerated review with timelines imposed; } \\
\text { engages external scientific experts }\end{array}$ \\
\hline Evidentiary Standards & Prefers de novo analyses of raw data & Primary focus is on the literature \\
\hline CDISC Standards & $\begin{array}{l}\text { Use by submitter accelerates FDA review, but } \\
\text { not required* }\end{array}$ & Not a requirement \\
\hline Measurement Science & $\begin{array}{l}\text { Engagement of Center for Devices and } \\
\text { Radiological Health (CDRH) }\end{array}$ & No formal medical device division \\
\hline Issues Letter of Support & YES & YES \\
\hline Role of Public Opinion & Opinion based on internal review & Seeks public opinion \\
\hline
\end{tabular}

*Clinical Registration studies started in 2017 will require CDISC standards for submission. 
is potentially relevant to the drug development programs of many sponsors. As such, the evidentiary requirements are greater for biomarker qualification than for employing a biomarker for a specific purpose in a single clinical trial. The risk/benefit ratio is key to consider in this context. Positive qualification decisions are publically communicated to the drug development and research communities through regulatory guidance documents by FDA's Center for Drug Evaluation and Research (CDER) [2, 4] and publically posted by the EMA and recommended as qualified DDTs across distinct programs.

As summarized in Table 1, although the FDA and EMA approach the process of biomarker qualification in a slightly different manner, they both are encouraging the scientific community to build reliable DDTs to accelerate the delivery of innovative medicines.

\section{REGULATORY ADVANCEMENTS OF AD BIOMARKERS}

In 2014, the FDA implemented a new initiative that aims to catalyze progress in the development of evidence for biomarker utility. As an additional novel regulatory tool to encourage biomarker development, the Letter of Support (LOS), is publicly posted on the FDA's website [71]. While a biomarker may still lack sufficient data to achieve full qualification, a LOS provides support that the biomarker has demonstrated promise based on the level of evidence that has been formally provided to regulators. The LOS encourages data sharing and implementation of globally accepted consensus standards to facilitate needed studies for qualification. In 2014, the EMA also launched this LOS mechanism to facilitate studies aimed at eventual qualification for the novel methodology under evaluation.

The EMA has issued qualification opinions on several AD biomarkers, including CSF $A \beta_{1-42}$ and $\mathrm{t}$-tau, for use in clinical trials $[14,30,31,70,72]$. In 2011, the EMA issued a qualification opinion on the use of CSF biomarkers for BMS-708163 (Avagacestat), which stated that "the CSF biomarkers signature based on low $A \beta_{1-42}$ and a high t-tau qualifies to identify MCI patients as close as possible to the prodromal stage of $\mathrm{AD}[26,73]$, who are at risk to evolve into AD dementia," [70]. The EMA followed this in 2012 with a qualification opinion on the use of CSF $\mathrm{A} \beta_{1-42}$ and t-tau, and/or PET amyloid imaging as biomarkers for enrichment of subjects with mild to moderate $\mathrm{AD}$ for clinical trials, in which they deter- mined that the "CSF biomarker signature based on $\mathrm{A} \beta_{1-42}$ and t-tau qualifies to identify patients with clinical diagnoses of mild-to-moderate $\mathrm{AD}$ who are at increased risk to have an underlying AD neuropathology, for the purposes of enriching a clinical trial population," [31].

While the FDA has not formally qualified any specific biomarker for $\mathrm{AD}$, they have included the use of biomarkers in the early AD draft guidance [33, 74] in the recent white paper on targeted drug development [75], and have issued two letters of support for AD biomarkers (CSF analytes [76] and low baseline hippocampal volume [77]) as prognostic biomarkers for enrichment.

The CAMD CSF Biomarker Team continues in the effort to seek qualification from the FDA on the use of CSF analytes as prognostic biomarkers for enrichment at the pre-dementia stage of clinical trials. The context of use for the CSF biomarkers is clinical trial enrichment or population stratification for analysis in amnestic MCI (aMCI) subjects. The purpose is to utilize the CSF analytes $A \beta_{1-42}$, $\mathrm{t}$-tau, and/or p-tau as prognostic markers for clinical trial enrichment to maximize the probability of longitudinal progression of decline over the duration of a 2-year clinical trial. The CAMD CSF effort currently does not include the diagnostic use and in vitro diagnostic (IVD) approval of CSF biomarkers, nor is the project currently considering these biomarkers as predicative biomarkers of treatment effects, nor as pharmacodynamic/response biomarkers, nor as monitoring or possibly surrogate endpoints of efficacy. CAMD's CSF biomarker team is presently at the Consultation and Advice Stage of biomarker qualification with FDA. To date, the team has provided FDA with data analyzed from ADNI and extensive literature supporting the proposed COU. Such data were deemed appropriate for FDA's issuance to CAMD of the LOS to encourage the further study and use of the CSF analytes $A \beta_{1-42}$, t-tau, and/or p-tau as exploratory prognostic biomarkers for enrichment in trials for AD [76].

The EMA has recently issued for comment "Draft guidance on the clinical investigation of medicines for the treatment of Alzheimer's disease and other dementias". Of particular importance in the draft guidance is commentary with respect to diagnostic criterion used, and how the use of different criterion may lead to different study populations of MCI (see section 5.2 of EMA guideline [6]). Importantly, the International Working Group (IWG) defines Prodromal AD as subjects with objective 
memory impairment and positive pathophysiological biomarker evidence as mandatory evidence. In contrast, the National Institute of Aging and Alzheimer's Association (NIA-AA) defines MCI due to $\mathrm{AD}$ as subjective or objective memory impairment and, while biomarker evidence is supportive, it is not mandatory. Furthermore, prodromal AD patients do not have functional impairments in instrumental activities of daily living (IADL) as defined by IWG, whereas NIA-AA accepts that patients with $\mathrm{MCI}$ due to $\mathrm{AD}$ can present with minor deficits in IADLs. Thus, because the use of different diagnostic criterion could result in different patient populations, caution will need to be taken when designing global development programs for future $\mathrm{AD}$ treatments, as well as determining cut-points for study inclusion. For considerations regarding the use of biomarkers for different contexts-of-use, see below [78]. Table 2 summarizes specific qualification opinions that are available for $\mathrm{AD}$ trial considerations.

Formal approvals have been issued by the FDA in the area of molecular neuroimaging biomarkers. The FDA has approved the use of three amyloid PET imaging radioligands for the detection of brain amyloid through the regular NDA application process of radiotracers [79]. However, these ligands are not yet approved for the diagnosis of AD nor are they qualified for use as enrichment biomarkers in drug development [80]. In contrast, the EMA has qualified the same amyloid tracers for the intended use as drug trial enrichment biomarkers [31].

\section{CHALLENGES TO SUCCESS}

The major challenge faced by the CAMD CSF Biomarker Team to qualify CSF A $\beta$ and tau measures is the difficulty in acquiring relevant clinical trial data from the sponsors of completed studies in the defined target population, predementia to MCI AD. In some cases, consent agreements failed to adequately anticipate the potential utility of stored samples and data analyses required for biomarker qualification. This challenge is especially notable for the CSF biomarkers owing to the difficulties of specimen collection via lumbar puncture. While the CAMD CSF Biomarker Team has encountered other issues, including the differences in pre-analytical sample handling, a lack of global standardization and harmonization of the available analytical methodologies, and a clear consensus on how to optimally analyze available data, these issues represent minor concerns when compared to the data access issue.

The implementation of clinical data standards, particularly those for biomarkers, is key to enabling future data integration and pooling. Despite the numerous publications that focus on specific parameters and pre-analytical factors recommended for all phases of CSF biomarker assay implementation [52, $59,81-85]$, at present there is no way to either enforce or incentivize sponsors to comply with these recommendations. Consequently, many clinical studies use different CSF assay conditions and parameters, making it exceedingly difficult to compare or pool data across trials [86].

Working with the Clinical Data Interchange Standards Consortium (CDISC), C-Path has successfully developed consensus data standards for multiple diseases, with specific focus on CNS conditions. CDISC's mission is to develop and support global, platform-independent data standards that enable information system interoperability to improve medical research and related areas of healthcare [87]. For AD CDISC standard development, a coalition of

Publically available biomarker qualification opinions in AD

\footnotetext{
A. CSF Biomarkers

1. Qualification opinion of Alzheimer's disease novel methodologies/biomarkers for the use of CSF A $\beta_{1-42}$ and t-tau and/or PET-amyloid imaging (positive/ negative) as biomarkers for enrichment, for use in regulatory clinical trials in mild and moderate Alzheimer's disease (EMA/CHMP/SAWP/893622/2011)

2. Qualification opinion of novel methodologies in the predementia stage of Alzheimer's disease: cerebrospinal fluid related biomarkers for drugs affecting amyloid burden (EMA/CHMP/SAWP/102001/2011)

B. Related Drug Development Tools

1. Qualification opinion of low hippocampal volume (atrophy) by MRI for use in clinical trials for regulatory purpose - in pre-dementia stage of Alzheimer's disease (EMA/CHMP/SAWP/809208/2011)

2. Qualification opinion of Alzheimer's disease novel methodologies/biomarkers for PET amyloid imaging (positive/negative) as a biomarker for enrichment for use - in predementia AD clinical trials 1285 (EMA/CHMP/SAWP/892998/2011)

3. Qualification opinion of a novel data driven model of disease progression and trial evaluation in mild and moderate Alzheimer's disease (EMA/CHMP/SAWP/567188/2013)
}

http://www.ema.europa.eu/ema/index.jsp?curl=pages/regulation/document_listing/document_listing_000319.jsp\#section8. 
academic experts, industry members, and regulatory agencies, in conjunction with ADNI leaders, collectively developed data standards in partnership with CDISC that included brain imaging, CSF, and cognitive endpoints. These standards were reviewed with respect to prevention trials with a focus on imaging (structural/MRI, PET) and CSF biomarkers. For CSF biomarkers, the relevant parameters identified include time and date of lumbar puncture, specific anatomical location of lumbar puncture (L3-L4 intervertebral space), gauge of spinal needle, and storage tube type. These important parameters have been highlighted in recent publications focused on standardization of CSF biomarkers [82]. Implementation of CDISC standards, particularly in the biomarkers arena, promises to facilitate improved efficiencies and harmonization in clinical trials. Notably, the FDA recommended the use of CDISC standards in the 2015 LOS regarding CSF biomarkers [76]. By 2017 there will be a requirement for all sponsors to submit data that comply with CDISC standards before it will be evaluated for regulatory feedback by CDER.

There is a critical need for biomarker data based on study designs and analytical methods that are acceptable to support regulatory decision-making. The major difficulties with the analytical methods employed in completed global multisite clinical trials relate to (i) the limited harmonization of results for CSF biomarkers obtained on different technology platforms, (ii) issues with some of the key performance characteristics, and/or (iii) the lack of an accepted RMP and CRM for each analyte. Initiatives to develop global calibration standards for CSF biomarkers are progressing well for $A \beta_{1-42}$ (see below), yet this is still an unmet need for other analytes. Improved methods ultimately are expected to provide high-throughput, random access and thus operationally practical methods that are both precise and accurate [88]. Such methods will also facilitate incorporation of CSF biomarkers into clinical trials of candidate pharmaceuticals with greater confidence in reliability and reproducibility of the measurements and interpretation of results.

There is an urgent need to share biomarker data from relevant clinical trials of candidate drugs initiating treatment at the prodromal $\mathrm{AD}$ stage. At the present time, there are few clinical trials that have been completed which have utilized biomarkers for inclusion in prodromal AD subjects. Two randomized controlled clinical trials of amyloid lowering candidate therapies, namely Avagacestat and Ganteneu- ramab [50, 89], were reported to have applied the NIA-AA (Avagacestat) or Dubois (Ganteneuramab/ ScarletRoad) criteria for subject selection, yet disclosures to date indicate that these studies did not employ the same assay and thus, used different cut-points. Nevertheless, even for drug trials that do not meet their primary endpoints and/or are discontinued, there are critical learnings to be gained by all stakeholders through data sharing. In addition, there is a need to share assay analytical performance data of existing and promising new biomarker platforms including next generation immunoassays under development or being commercialized.

Increased scientific rigor in biomarker research is urgently needed to develop, validate, and ultimately qualify biomarkers $[90,91]$. There is a need for properly designed studies with adequate power to demonstrate the required reproducibility, sensitivity to diagnostic differences and clinical change, and ability to calibrate across multiple platforms. Recent recommendations support the appropriate evidentiary standards required for assay validation for immunoassays [92]. To obtain data from diverse stakeholders, including diagnostic manufacturers, poses particular challenges since in many cases the assays are advancing via various regulatory pathways toward diagnostic use. This is naturally dependent on a thriving competitive landscape for diagnostic companies and assay manufacturers to either independently or in partnership with pharmaceutical industry collaborators, develop companion or stand-alone diagnostic tests for regulatory approval. However, a key risk for the field is that when a drug candidate fails in $\mathrm{AD}$ and the sponsor may downsize or eliminate its investments, the information obtained on that biomarker may be lost and the sharing of that information significantly delayed or halted. Valuable data, knowledge, and investments are at risk, hindering the field's advancement of that biomarker. Moreover, such challenges augment the overall risk of drug development in this disease area in critical need for effective treatments.

\section{CONCLUSION AND RECOMMENDATIONS FOR THE FUTURE}

To achieve regulatory qualification by the FDA of CSF biomarkers for use in clinical trials in subjects with early $\mathrm{AD}$, the authors recommend several steps to accelerate future biomarker development and increase success in therapeutic development. 


\section{Global Initiatives Focused on AD CSF Biomarkers}

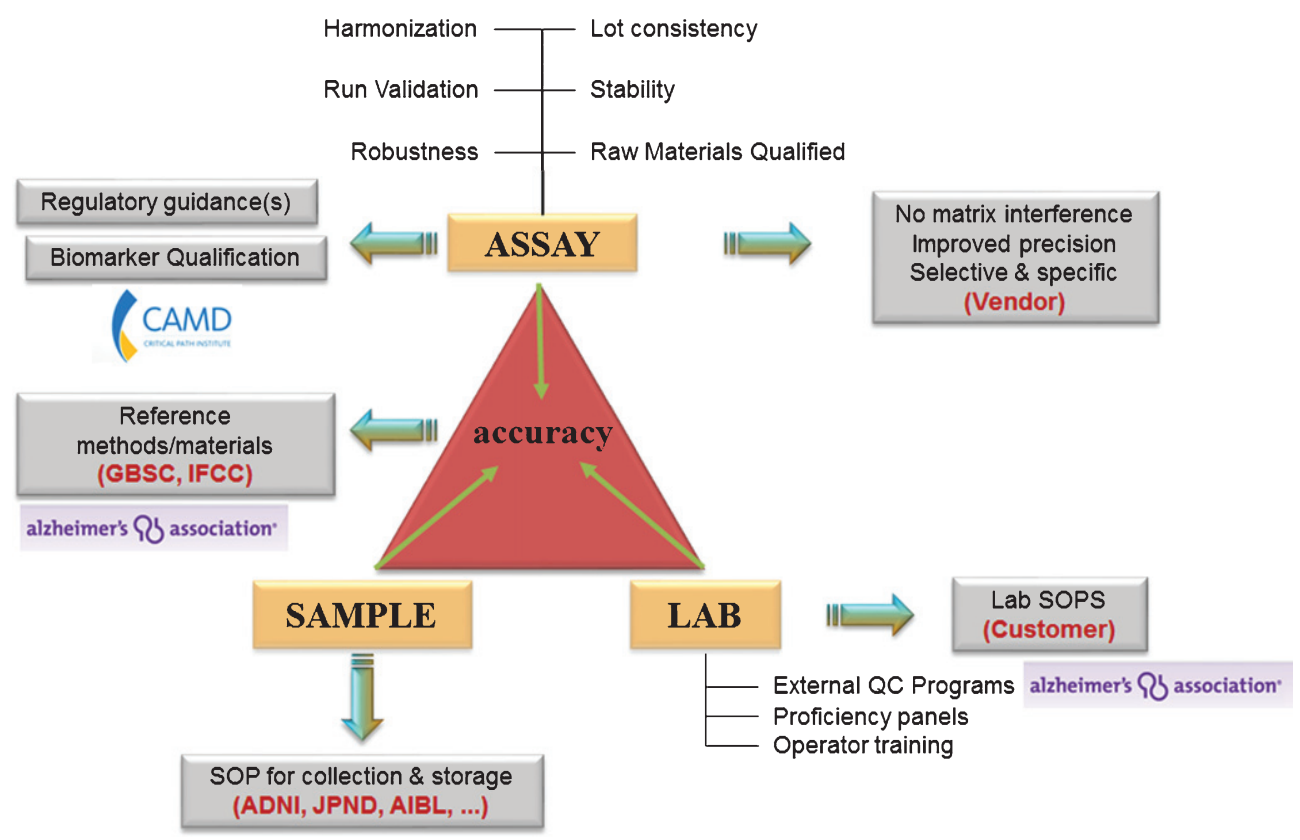

Fig. 3. Current global initiatives focused on AD CSF biomarkers. Involvement of worldwide consortia in the standardization of CSF biomarker analysis at the level of the assay, the sample, and the laboratory. Grey box: the need for the future. ADNI, Alzheimer's disease neuroimaging initiative; AIBL, The Australian Imaging, Biomarker \& Lifestyle Flagship Study of Ageing; CAMD, Coalition Against Major Diseases; GBSC, Global Biomarker Standardization Initiative; IFCC, International Federation of Clinical Chemistry; JPND, EU Joint Programme Neurodegenerative Disease Research (JPND); QC, quality control; SOP, standard operating procedure.

Table 3

CAMD's recommendations to advance CSF biomarkers for AD

\section{Regulatory Sciences}

- Harmonization of diagnostic criterion (IWG versus NIA-AA) that defines patient populations studied

- Expanded alliances of all stakeholder groups, particularly precompetitive consortium working on discovery, validation, and regulatory endorsement of AD biomarkers

- Full engagement and active participation of relevant diagnostic companies and manufacturers, particularly as contributors of data, under confidentiality

- Continued engagement with submission of data analyses and methodology to regulatory agencies to ensure that qualification efforts can progress efficiently

- Dedicated resources to support quantitative understanding of AD disease progression from pre-symptomatic to end-stage disease, including assessment of sources of variability

- Increased recognition that a single biomarker will likely be insufficient to understand AD disease progression and the need for increased support for quantitative modeling of AD including multiple covariates

Data Standards and Data Sharing

- Use of AD CDISC biomarker and clinical data standards in ongoing and prospective clinical trials of subjects with AD

- Harmonizing data generated by different technology platforms, as well as documentation of the commutability of the analytic system with a reference method

- Sharing data at the individual patient level from relevant clinical trials, including biomarker data and accompanying clinical data on all subjects at baseline and follow up, from independent cohorts and international initiatives

Assay Validation

- Sharing bioanalytical assay performance data supporting reliability and reproducibility of all relevant CSF biomarker assay platforms

- Classification and identification of the assay analytical expectations and performance requirements required to support biomarker qualification

These steps are focused on collaborative efforts that include data standards, data sharing, and validation of biomarker assays. FDA qualification of AD CSF biomarkers in clinical trials is expected to improve the chances of success of new, greatly needed therapies for patients with $\mathrm{AD}$. 
By implementing the suggested actions below, collaboration will become the norm, data standards and data sharing will be recognized as a must, and standardization and harmonization of assays will be a cornerstone practice. Figure 3 illustrates the current activities within the CSF biomarker space, and indicates how CAMD's focus on regulatory qualification has led to alignment across consortia. Working collectively to share costs and risks, international consortia such as CAMD are steadily making progress toward scientific, clinical, and regulatory acceptance of CSF biomarkers for AD.

CAMD's recommendations to advance CSF biomarkers for $\mathrm{AD}$ are summarized in Table 3, and are focused on three key areas: regulatory sciences, data standards and data sharing, and assay validation.

\section{ACKNOWLEDGMENTS}

The authors gratefully thank Lisa Bain, scientific and medical writer, for her contributions to this manuscript. CAMD acknowledges the support and contributions of the following FDA colleagues: Dr. Shashi Amur, Dr. ShaAvhrée Buckman-Garner, and Dr. Nick Kozauer. We thank Dr. Amy Porter (Critical Path Institute), Dr. David Brill (Boehringer Ingelheim), Dr. Alvydas Mikulskis (Biogen), and Richard Mohs (Chief Scientific Officer, Global Alzheimer's Platform Foundation) for their review of the manuscript. This work was partially funded by FDA grant \#5U01FD003865, and the member organizations of CAMD.

Authors' disclosures available online (http://j-alz. com/manuscript-disclosures/16-0573r1).

\section{REFERENCES}

[1] Woodcock J, Buckman S, Goodsaid F, Walton MK, Zineh I (2011) Qualifying biomarkers for use in drug development: A US Food and Drug Administration overview. Expert Opin Med Diagn 5, 369-374.

[2] Amur S, LaVange L, Zineh I, Buckman-Garner S, Woodcock J (2015) Biomarker qualification: Toward a multiple stakeholder framework for biomarker development, regulatory acceptance, and utilization. Clin Pharmacol Ther 98, 34-46.

[3] Qualification of novel methodologies for drug development: Guidance to applicants. http://www.ema.europa.eu/ docs/en_GB/document_library/Regulatory_and_procedural guideline/2009/10/WC500004201.pdf, Last updated November 10, 2014, Accessed on May 11, 2016.

[4] Amur SG, Sanyal S, Chakravarty AG, Noone MH, Kaiser J, McCune S, Buckman-Garner SY (2015) Building a roadmap to biomarker qualification: Challenges and opportunities. Biomark Med 9, 1095-1105.

[5] BEST (Biomarkers, EndpointS, and other Tools) Resource, http://www.ncbi.nlm.nih.gov/books/NBK338448/, Last updated April 28, 2016, Accessed on May 11, 2016.

[6] European Medicines Agency. Draft guideline on the clinical investigation of medicines for the treatment of Alzheimer's disease and other dementias, http://www.ema. europa.eu/docs/en_GB/document_library/Regulatory_and_ procedural_guideline/2009/10/WC500004201.pdf, Last updated January 28, 2016, Accessed on May 11, 2016.

[7] Romero K, de Mars M, Frank D, Anthony M, Neville J, Kirby L, Smith K, Woosley RL (2009) The Coalition Against Major Diseases: Developing tools for an integrated drug development process for Alzheimer's and Parkinson's diseases. Clin Pharmacol Ther 86, 365-367.

[8] Stephenson D, Brumfield M, Romero K, Woodcock J, Zineh I, Reiman EM, Tanner C, Mohs R, Koroshetz W, Nicholas T, Bain LJ, Hill DLG, Shaw L, Luthman J, Ropacki M, Meibach R, Loupos P, Marek K, Hendrix J, Karran E, Vradenburg G, Motohashi K, Cedarbaum JM, Gordon MF (2015) Alzheimer's and Parkinson's diseases face common challenges in therapeutic development: Role of the Precompetitive Consortium, Coalition Against Major Diseases. J Alzheimers Dis Parkinsonism 5, 1-5.

[9] Woosley RL, Myers RT, Goodsaid F (2010) The Critical Path Institute's approach to precompetitive sharing and advancing regulatory science. Clin Pharmacol Ther 87, 530533.

[10] US Food and Drug Administratoin, Innovation or stagnation: Challenges and opportunity on the critical path to new medical products, http://www.fda.gov/downloads/ ScienceResearch/SpecialTopics/CriticalPathInitiative/Criti calPathOpportunitiesReports/ucm113411.pdf, Last updated March 16, 2004, Accessed on May 11, 2016.

[11] Brumfield M (2014) The Critical Path Institute: Transforming competitors into collaborators. Nat Rev Drug Discov 13, 785-786.

[12] Hill DLG, Schwarz AJ, Isaac M, Pani L, Vamvakas S, Hemmings R, Carrillo MC, Yu P, Sun J, Beckett L, Boccardi M, Brewer J, Brumfield M, Cantillon M, Cole PE, Fox N, Frisoni GB, Jack C, Kelleher T, Luo F, Novak G, Maguire P, Meibach R, Patterson P, Bain L, Sampaio C, Raunig D, Soares H, Suhy J, Wang H, Wolz R, Stephenson D (2014) Coalition Against Major Diseases/European Medicines Agency biomarker qualification of hippocampal volume for enrichment of clinical trials in predementia stages of Alzheimer's disease. Alzheimers Dement 10, 421429.e3.

[13] European Medicines Agency. Qualification opinion of low hippocampal volume (atrophy) by MRI for use in clinical trials for regulatory purpose - in pre-dementia stage of Alzheimer's disease, http://www.ema.europa.eu/ docs/en_GB/document_library/Regulatory_and_procedural_ guideline/2011/12/WC500118737.pdf, Last updated November 17, 2011, Accessed on May 11, 2016.

[14] Romero K, Ito K, Rogers JA, Polhamus D, Qiu R, Stephenson D, Mohs R, Lalonde R, Sinha V, Wang Y, Brown D, Isaac M, Vamvakas S, Hemmings R, Pani L, Bain LJ, Corrigan B, Alzheimer's Disease Neuroimaging Initiative, Coalition Against Major Diseases (2015) The future is now: Model-based clinical trial design for Alzheimer's disease. Clin Pharmacol Ther 97, 210-214.

[15] Neville J, Kopko S, Broadbent S, Avilés E, Stafford R, Solinsky CM, Bain LJ, Cisneroz M, Romero K, Stephenson 
D, Coalition Against Major Diseases (2015) Development of a unified clinical trial database for Alzheimer's disease. Alzheimers Dement 11, 1212-1221.

[16] Broich K, Weiergräber M, Hampel H (2011) Biomarkers in clinical trials for neurodegenerative diseases: Regulatory perspectives and requirements. Prog Neurobiol 95, 498-500.

[17] Liu E, Luthman J, Cedarbaum JM, Schmidt ME, Cole PE, Hendrix J, Carrillo MC, Jones-Davis D, Tarver E, Novak G, De Santi S, Soares HD, Potter WZ, Siemers E, Schwarz AJ (2015) Perspective: The Alzheimer's Disease Neuroimaging Initiative and the role and contributions of the Private Partner Scientific Board (PPSB). Alzheimers Dement 11, 840-849.

[18] Kuhlmann J, Andreasson U, Pannee J, Bjerke M, Portelius M, Leinenbach AF, Bittner T, Korecka M, Jenkins RG, Vanderstichele HMJ, Stoops E, Lewczuk P, Shaw LM, Zegers I, Schimmel H, Zetterberg H, Blennow K, on behalf of the IFCC Working Group on Standardisation of CSF proteins (WG-CSF) (2016) CSF A 1 1-42 - an excellent but complicated Alzheimer's biomarker - a route to standardisation. Clin Chim Acta. doi: 10.1016/j.cca.2016.05.014

[19] Carrillo MC, Blennow K, Soares H, Lewczuk P, Mattsson N, Oberoi P, Umek R, Vandijck M, Salamone S, Bittner T, Shaw LM, Stephenson D, Bain L, Zetterberg H (2013) Global standardization measurement of cerebral spinal fluid for Alzheimer's disease: An update from the Alzheimer's Association Global Biomarkers Consortium. Alzheimers Dement 9, 137-140.

[20] Hampel H, Frank R, Broich K, Teipel SJ, Katz RG, Hardy J, Herholz K, Bokde ALW, Jessen F, Hoessler YC, Sanhai WR, Zetterberg H, Woodcock J, Blennow K (2010) Biomarkers for Alzheimer's disease: Academic, industry and regulatory perspectives. Nat Rev Drug Discov 9, 560-574.

[21] Cummings JL, Morstorf T, Zhong K (2014) Alzheimer's disease drug-development pipeline: Few candidates, frequent failures. Alzheimers Res Ther 6, 37.

[22] Karran E, Hardy J (2014) A critique of the drug discovery and phase 3 clinical programs targeting the amyloid hypothesis for Alzheimer disease. Ann Neurol 76, 185-205.

[23] Doody RS, Thomas RG, Farlow M, Iwatsubo T, Vellas B, Joffe S, Kieburtz K, Raman R, Sun X, Aisen PS, Siemers E, Liu-Seifert H, Mohs R, Alzheimer's Disease Cooperative Study Steering Committee, Solanezumab Study Group (2014) Phase 3 trials of solanezumab for mild-to-moderate Alzheimer's disease. $N$ Engl J Med 370, 311-321.

[24] Cavedo E, Lista S, Khachaturian Z, Aisen P, Amouyel P, Herholz K, Jack CR, Sperling R, Cummings J, Blennow K, O'Bryant S, Frisoni GB, Khachaturian A, Kivipelto M, Klunk W, Broich K, Andrieu S, de Schotten MT, Mangin J-F, Lammertsma AA, Johnson K, Teipel S, Drzezga A, Bokde A, Colliot O, Bakardjian H, Zetterberg H, Dubois B, Vellas B, Schneider LS, Hampel H (2014) The road ahead to cure Alzheimer's disease: Development of biological markers and neuroimaging methods for prevention trials across all stages and target populations. J Prev Alzheimers Dis 1, 181-202.

[25] Monsell SE, Kukull WA, Roher AE, Maarouf CL, Serrano G, Beach TG, Caselli RJ, Montine TJ, Reiman EM (2015) Characterizing apolipoprotein E $\varepsilon 4$ carriers and noncarriers with the clinical diagnosis of mild to moderate Alzheimer dementia and minimal $\beta$-amyloid peptide plaques. JAMA Neurol 72, 1124-1131.

[26] Dubois B, Hampel H, Feldman HH, Scheltens P, Aisen P, Andrieu S, Bakardjian H, Benali H, Bertram L, Blennow K, Broich K, Cavedo E, Crutch S, Dartigues J-F, Duyckaerts C,
Epelbaum S, Frisoni GB, Gauthier S, Genthon R, Gouw AA, Habert M-O, Holtzman DM, Kivipelto M, Lista S, Molinuevo J-L, O’Bryant SE, Rabinovici GD, Rowe C, Salloway S, Schneider LS, Sperling R, Teichmann M, Carrillo MC, Cummings J, Jack CR, Proceedings of the Meeting of the International Working Group (IWG), the American Alzheimer's Association on "The Preclinical State of AD", July 23, 2015, Washington DC, USA (2016) Preclinical Alzheimer's disease: Definition, natural history, and diagnostic criteria. Alzheimers Dement 12, 292-323.

[27] Albert MS, DeKosky ST, Dickson D, Dubois B, Feldman HH, Fox NC, Gamst A, Holtzman DM, Jagust WJ, Petersen RC, Snyder PJ, Carrillo MC, Thies B, Phelps CH (2011) The diagnosis of mild cognitive impairment due to Alzheimer's disease: Recommendations from the National Institute on Aging-Alzheimer's Association workgroups on diagnostic guidelines for Alzheimer's disease. Alzheimers Dement 7, 270-279.

[28] Jack CR, Knopman DS, Jagust WJ, Shaw LM, Aisen PS, Weiner MW, Petersen RC, Trojanowski JQ (2010) Hypothetical model of dynamic biomarkers of the Alzheimer's pathological cascade. Lancet Neurol 9, 119-128.

[29] Dickerson BC, Wolk DA, Alzheimer's Disease Neuroimaging Initiative (2013) Biomarker-based prediction of progression in MCI: Comparison of AD signature and hippocampal volume with spinal fluid amyloid- $\beta$ and tau. Front Aging Neurosci 5, 55.

[30] Haas M, Mantua V, Haberkamp M, Pani L, Isaac M, ButlenDucuing F, Vamvakas S, Broich K (2015) The European Medicines Agency's strategies to meet the challenges of Alzheimer disease. Nat Rev Drug Discov 14, 221-222.

[31] European Medicines Agency, Qualification opinion of Alzheimer's disease novel methodologies/biomarkers for the use of CSF A $\beta$ 1-42 and t-tau and/or PET-amyloid imaging (positive/ negative) as biomarkers for enrichment, for use in regulatory clinical trials in mild and moderate Alzheimer's disease, http://www.ema.europa.eu/ docs/en_GB/document_library/Regulatory_and_procedural_ guideline/2012/04/WC500125019.pdf, Last updated February 16, 2012, Accessed on May 11, 20136.

[32] US Food and Drug Administration, Guidance for Industry Enrichment Strategies for Clinical Trials to Support Approval of Human Drugs and Biological Products, http://www.fda.gov/downloads/Drugs/GuidanceCompliance RegulatoryInformation/Guidances/UCM332181.pdf, Last updated December 2012, Accessed on May 11, 2016.

[33] Kozauer N, Katz R (2013) Regulatory innovation and drug development for early-stage Alzheimer's disease. $N$ Engl $J$ Med 368, 1169-1171.

[34] Höglund K, Fourier A, Perret-Liaudet A, Zetterberg H, Blennow K, Portelius E (2015) Alzheimer's disease-Recent biomarker developments in relation to updated diagnostic criteria. Clin Chim Acta 449, 3-8.

[35] Weiner MW, Veitch DP, Aisen PS, Beckett LA, Cairns NJ, Cedarbaum J, Donohue MC, Green RC, Harvey D, Jack CR, Jagust W, Morris JC, Petersen RC, Saykin AJ, Shaw L, Thompson PM, Toga AW, Trojanowski JQ, Alzheimer's Disease Neuroimaging Initiative (2015) Impact of the Alzheimer's disease neuroimaging initiative, 2004 to 2014. Alzheimers Dement 11, 865-884.

[36] Lleó A, Cavedo E, Parnetti L, Vanderstichele H, Herukka SK, Andreasen N, Ghidoni R, Lewczuk P, Jeromin A, Winblad B, Tsolaki M, Mroczko B, Visser PJ, Santana I, Svenningsson P, Blennow K, Aarsland D, Molinuevo JL, Zetterberg H, Mollenhauer B (2015) Cerebrospinal fluid 
biomarkers in trials for Alzheimer and Parkinson diseases. Nat Rev Neurol 11, 41-55.

[37] Olsson B, Lautner R, Andreasson U, Öhrfelt A, Portelius E, Bjerke M, Hölttä M, Rosén C, Olsson C, Strobel G, Wu E, Dakin K, Petzold M, Blennow K, Zetterberg H (2016) CSF and blood biomarkers for the diagnosis of Alzheimer's disease: A systematic review and meta-analysis. Lancet Neurol 15, 673-684.

[38] Strozyk D, Blennow K, White LR, Launer LJ (2003) CSF Abeta 42 levels correlate with amyloid-neuropathology in a population-based autopsy study. Neurology 60, 652-656.

[39] Engelborghs S, De Vreese K, Van de Casteele T, Vanderstichele H, Van Everbroeck B, Cras P, Martin J-J, Vanmechelen E, De Deyn PP (2008) Diagnostic performance of a CSF-biomarker panel in autopsy-confirmed dementia. Neurobiol Aging 29, 1143-1159.

[40] Struyfs H, Molinuevo JL, Martin JJ, De Deyn PP, Engelborghs S (2014) Validation of the AD-CSF-index in autopsy-confirmed Alzheimer's disease patients and healthy controls. J Alzheimers Dis 41, 903-909.

[41] Blennow K, Hampel H, Weiner M, Zetterberg H (2010) Cerebrospinal fluid and plasma biomarkers in Alzheimer disease. Nat Rev Neurol 6, 131-144.

[42] Landau SM, Lu M, Joshi AD, Pontecorvo M, Mintun MA, Trojanowski JQ, Shaw LM, Jagust WJ, Alzheimer's Disease Neuroimaging Initiative (2013) Comparing positron emission tomography imaging and cerebrospinal fluid measurements of $\beta$-amyloid. Ann Neurol 74, 826-836.

[43] Skoog I, Davidsson P, Aevarsson O, Vanderstichele H, Vanmechelen E, Blennow K (2003) Cerebrospinal fluid beta-amyloid 42 is reduced before the onset of sporadic dementia: A population-based study in 85-year-olds. Dement Geriatr Cogn Disord 15, 169-176.

[44] Hansson O, Zetterberg H, Buchhave P, Londos E, Blennow K, Minthon L (2006) Association between CSF biomarkers and incipient Alzheimer's disease in patients with mild cognitive impairment: A follow-up study. Lancet Neurol 5, 228-234.

[45] Wallin AK, Blennow K, Zetterberg H, Londos E, Minthon L, Hansson O (2010) CSF biomarkers predict a more malignant outcome in Alzheimer disease. Neurology 74, 15311537.

[46] Milenkovic I, Petrov T, Kovacs GG (2014) Patterns of hippocampal tau pathology differentiate neurodegenerative dementias. Dement Geriatr Cogn Disord 38, 375-388.

[47] Holtzman DM (2011) CSF biomarkers for Alzheimer's disease: Current utility and potential future use. Neurobiol Aging 32(Suppl 1), S4-S9.

[48] Blennow K, Dubois B, Fagan AM, Lewczuk P, de Leon MJ, Hampel H (2015) Clinical utility of cerebrospinal fluid biomarkers in the diagnosis of early Alzheimer's disease. Alzheimers Dement 11, 58-69.

[49] Li J-Q, Tan L, Wang H-F, Tan M-S, Tan L, Xu W, Zhao Q-F, Wang J, Jiang T, Yu J-T (2016) Risk factors for predicting progression from mild cognitive impairment to Alzheimer's disease: A systematic review and meta-analysis of cohort studies. J Neurol Neurosurg Psychiatry 87, 476-484.

[50] Coric V, Salloway S, van Dyck CH, Dubois B, Andreasen N, Brody M, Curtis C, Soininen H, Thein S, Shiovitz T, Pilcher G, Ferris S, Colby S, Kerselaers W, Dockens R, Soares H, Kaplita S, Luo F, Pachai C, Bracoud L, Mintun M, Grill JD, Marek K, Seibyl J, Cedarbaum JM, Albright C, Feldman HH, Berman RM (2015) Targeting prodromal Alzheimer disease with avagacestat: A randomized clinical trial. JAMA Neurol 72, 1324-1333.
[51] Mattsson N, Andreasson U, Persson S, Carrillo MC, Collins S, Chalbot S, Cutler N, Dufour-Rainfray D, Fagan AM, Heegaard NHH, Robin Hsiung G-Y, Hyman B, Iqbal K, Kaeser SA, Käser SA, Lachno DR, Lleó A, Lewczuk P, Molinuevo JL, Parchi P, Regeniter A, Rissman RA, Rissman R, Rosenmann H, Sancesario G, Schröder J, Shaw LM, Teunissen CE, Trojanowski JQ, Vanderstichele H, Vandijck M, Verbeek MM, Zetterberg H, Blennow K, Alzheimer's Association QC Program Work Group (2013) CSF biomarker variability in the Alzheimer's Association quality control program. Alzheimers Dement 9, 251-261.

[52] del Campo M, Mollenhauer B, Bertolotto A, Engelborghs S, Hampel H, Simonsen AH, Kapaki E, Kruse N, Le Bastard N, Lehmann S, Molinuevo JL, Parnetti L, Perret-Liaudet A, Sáez-Valero J, Saka E, Urbani A, Vanmechelen E, Verbeek M, Visser PJ, Teunissen C (2012) Recommendations to standardize preanalytical confounding factors in Alzheimer's and Parkinson's disease cerebrospinal fluid biomarkers: An update. Biomark Med 6, 419-430.

[53] Vanderstichele H, Bibl M, Engelborghs S, Le Bastard N, Lewczuk P, Molinuevo JL, Parnetti L, Perret-Liaudet A, Shaw LM, Teunissen C, Wouters D, Blennow K (2012) Standardization of preanalytical aspects of cerebrospinal fluid biomarker testing for Alzheimer's disease diagnosis: A consensus paper from the Alzheimer's Biomarkers Standardization Initiative. Alzheimers Dement 8, 65-73.

[54] International Federation of Clinical Chemistry and Laboratory Medicine, CSF-Proteins (WG-CSF), http://www.ifcc. org/ifcc-scientific-division/sd-working-groups/csf-proteins -wg-csf/, Last updated 2016, Accessed on May 11, 2016.

[55] Pannee J, Portelius E, Oppermann M, Atkins A, Hornshaw M, Zegers I, Höjrup P, Minthon L, Hansson O, Zetterberg H, Blennow K, Gobom J (2013) A selected reaction monitoring (SRM)-based method for absolute quantification of $A \beta 38$, $\mathrm{A} \beta 40$, and $\mathrm{A} \beta 42$ in cerebrospinal fluid of Alzheimer's disease patients and healthy controls. J Alzheimers Dis 33, 1021-1032.

[56] Pannee J, Gobom J, Shaw LM, Korecka M, Chambers EE, Lame M, Jenkins R, Mylott W, Carrillo MC, Zegers I, Zetterberg H, Blennow K, Portelius E (2016) Round robin test on quantification of amyloid- $\beta$ 1-42 in cerebrospinal fluid by mass spectrometry. Alzheimers Dement 12, 55-59.

[57] Leinenbach A, Pannee J, Dülffer T, Huber A, Bittner $\mathrm{T}$, Andreasson U, Gobom J, Zetterberg H, Kobold U, Portelius E, Blennow K, IFCC Scientific Division Working Group on CSF proteins (2014) Mass spectrometry-based candidate reference measurement procedure for quantification of amyloid- $\beta$ in cerebrospinal fluid. Clin Chem $\mathbf{6 0}$, 987-994.

[58] McAvoy T, Lassman ME, Spellman DS, Ke Z, Howell BJ, Wong O, Zhu L, Tanen M, Struyk A, Laterza OF (2014) Quantification of tau in cerebrospinal fluid by immunoaffinity enrichment and tandem mass spectrometry. Clin Chem 60, 683-689.

[59] Fourier A, Portelius E, Zetterberg H, Blennow K, Quadrio I, Perret-Liaudet A (2015) Pre-analytical and analytical factors influencing Alzheimer's disease cerebrospinal fluid biomarker variability. Clin Chim Acta 449, 9-15.

[60] Korecka M, Waligorska T, Figurski M, Toledo JB, Arnold SE, Grossman M, Trojanowski JQ, Shaw LM (2014) Qualification of a surrogate matrix-based absolute quantification method for amyloid- $\beta_{42}$ in human cerebrospinal fluid using 2D UPLC-tandem mass spectrometry. J Alzheimers Dis $\mathbf{4 1}$, 441-451. 
[61] Lewczuk P, Lelental N, Spitzer P, Maler JM, Kornhuber J (2015) Amyloid- $\beta$ 42/40 cerebrospinal fluid concentration ratio in the diagnostics of Alzheimer's disease: Validation of two novel assays. J Alzheimers Dis 43, 183-191.

[62] Bjerke M, Andreasson U, Kuhlmann J, Portelius E, Pannee J, Lewczuk P, Umek RM, Vanmechelen E, Vanderstichele H, Stoops E, Lewis J, Vandijck M, Kostanjevecki V, Jeromin A, Salamone SJ, Schmidt O, Matzen A, Madin K, Eichenlaub U, Bittner T, Shaw LM, Zegers I, Zetterberg H, Blennow K (2016) Assessing the commutability of reference material formats for the harmonization of amyloid beta measurements. Clin Chem Lab Med 54, 1177-1191.

[63] Soldan A, Pettigrew C, Cai Q, Wang M-C, Moghekar AR, O'Brien RJ, Selnes OA, Albert MS, BIOCARD Research Team (2016) Hypothetical preclinical Alzheimer disease groups and longitudinal cognitive change. JAMA Neurol 73, 698-705.

[64] Barthélemy NR, Gabelle A, Hirtz C, Fenaille F, Sergeant N, Schraen-Maschke S, Vialaret J, Buée L, Junot C, Becher F, Lehmann S (2016) Differential mass spectrometry profiles of tau protein in the cerebrospinal fluid of patients with Alzheimer's disease, progressive supranuclear palsy, and dementia with Lewy bodies. J Alzheimers Dis 51, 10331043.

[65] Berlyand Y, Weintraub D, Xie SX, Mellis IA, Doshi J, Rick J, McBride J, Davatzikos C, Shaw LM, Hurtig H, Trojanowski JQ, Chen-Plotkin AS (2016) An Alzheimer's disease-derived biomarker signature identifies Parkinson's disease patients with dementia. PloS One 11, e0147319.

[66] Buckler AJ, Bresolin L, Dunnick NR, Sullivan DC, Aerts HJWL, Bendriem B, Bendtsen C, Boellaard R, Boone JM, Cole PE, Conklin JJ, Dorfman GS, Douglas PS, Eidsaunet W, Elsinger C, Frank RA, Gatsonis C, Giger ML, Gupta SN, Gustafson D, Hoekstra OS, Jackson EF, Karam L, Kelloff GJ, Kinahan PE, McLennan G, Miller CG, Mozley PD, Muller KE, Patt R, Raunig D, Rosen M, Rupani H, Schwartz LH, Siegel BA, Sorensen AG, Wahl RL, Waterton JC, Wolf W, Zahlmann G, Zimmerman B (2011) Quantitative imaging test approval and biomarker qualification: Interrelated but distinct activities. Radiology 259, 875-884.

[67] US Food and Drug Administration, Guidance for Industry and FDA Staff. Qualification Process for Drug Development Tools, http://www.fda.gov/downloads/drugs/guidancecom plianceregulatoryinformation/guidances/ucm230597.pdf, Last updated January 2014, Accessed on May 11, 2016.

[68] Woodcock J (2014) Paving the critical path of drug development: The CDER perspective. Nat Rev Drug Discov 13, 783-784.

[69] Lavezzari G, Womack AW (2016) Industry perspectives on biomarker qualification. Clin Pharmacol Ther 99, 208-213.

[70] European Medicines Agency, Qualification Opinion of Alzheimer's Disease Novel Methodologies/biomarkers for BMS-708163, http://www.ema.europa.eu/docs/en_GB/ document_library/Regulatory_and_procedural_guideline/ 2011/02/WC500102018.pdf, Last updated February 10, 2011, Accessed on May 11, 2016.

[71] US Food and Drug Administration, Drug Development Tools (DDT) Letters of Support, http://www.fda.gov/Drugs/ DevelopmentApprovalProcess/ucm 434382.htm, Last updated April 20, 2016, Accessed on May 11, 2016.

[72] European Medicines Agency, Qualification opinion of Alzheimer's disease novel methodologies/biomarkers for PET amyloid imaging (positive/negative) as a biomarker for enrichment, for use in regulatory clinical trials in predementia Alzheimer's disease, http://www.ema.europa.eu/
docs/en_GB/document_library/Regulatory_and_procedural_ guideline/2012/04/WC500125018.pdf, Last updated February 16, 2012, Accessed on May 11, 2016.

[73] Dubois B, Feldman HH, Jacova C, Dekosky ST, BarbergerGateau P, Cummings J, Delacourte A, Galasko D, Gauthier S, Jicha G, Meguro K, O’brien J, Pasquier F, Robert P, Rossor M, Salloway S, Stern Y, Visser PJ, Scheltens P (2007) Research criteria for the diagnosis of Alzheimer's disease: Revising the NINCDS-ADRDA criteria. Lancet Neurol 6, 734-746.

[74] US Food and Drug Administration, Guidance for Industry Alzheimer's Disease: Developing Drugs for the Treatment of Early Stage Disease, http://www.fda.gov/downloads/ drugs/guidancecomplianceregulatoryinformation/guidan ces/ucm338287.pdf, Last updated February 2013, Accessed on May 11, 2016.

[75] US Food and Drug Administration. Targeted Drug Development: Why Are Many Diseases Lagging Behind? http://www.fda.gov/AboutFDA/ReportsManualsForms/Rep orts/ucm454955.htm, Last updated July 16, 2015, Accessed on May 11, 2016

[76] US Food and Drug Administration, Biomarker Letter of Support for use of CSF analytes A $\beta 1-42$, tau and phosphotau, as exploratory prognostic biomarkers for enrichment in clinical trials in Alzheimer's disease, http://www.fda. gov/downloads/Drugs/DevelopmentApprovalProcess/UCM 439713.pdf., Last updated February 26, 2015, Accessed on May 11, 2016.

[77] US Food and Drug Administration. Biomarker Letter of Support for baseline low hippocampal volume measured by MRI as an exploratory prognostic biomarker for enrichment in clinical trials for Alzheimer's disease, http://www.fda. gov/downloads/Drugs/DevelopmentApprovalProcess/UCM 439714.pdf, Last updated March 10, 2015, Accessed on May 11, 2016.

[78] European Medicines Agency, Qualification of novel methodologies for medicine development, http://www.ema. europa.eu/ema/index.jsp?curl=pages/regulation/document_ listing/document_listing_000319.jsp\#section8, Last updated 2016, Accessed on May 11, 2016.

[79] Kepe V, Moghbel MC, Långström B, Zaidi H, Vinters HV, Huang S-C, Satyamurthy N, Doudet D, Mishani E, Cohen RM, Høilund-Carlsen PF, Alavi A, Barrio JR (2013) Amyloid- $\beta$ positron emission tomography imaging probes: A critical review. J Alzheimers Dis 36, 613-631.

[80] Leuzy A, Zimmer ER, Heurling K, Rosa-Neto P, Gauthier S (2014) Use of amyloid PET across the spectrum of Alzheimer's disease: Clinical utility and associated ethical issues. Amyloid 21, 143-148.

[81] Le Bastard N, De Deyn PP, Engelborghs S (2015) Importance and impact of preanalytical variables on Alzheimer disease biomarker concentrations in cerebrospinal fluid. Clin Chem 61, 734-743.

[82] Leitão MJ, Baldeiras I, Herukka S-K, Pikkarainen M, Leinonen V, Simonsen AH, Perret-Liaudet A, Fourier A, Quadrio I, Veiga PM, de Oliveira CR (2015) Chasing the effects of pre-analytical confounders - a multicenter study on CSF-AD biomarkers. Front Neurol 6, 153.

[83] Park SA, Kang JH, Kang ES, Ki CS, Roh JH, Youn YC, Kim SY, Kim SY (2015) A consensus in Korea regarding a protocol to reduce preanalytical sources of variability in the measurement of the cerebrospinal fluid biomarkers of Alzheimer's disease. J Clin Neurol 11, 132-141.

[84] Palmqvist S, Zetterberg H, Blennow K, Vestberg S, Andreasson U, Brooks DJ, Owenius R, Hägerström D, 
Wollmer P, Minthon L, Hansson O (2014) Accuracy of brain amyloid detection in clinical practice using cerebrospinal fluid $\beta$-amyloid 42: A cross-validation study against amyloid positron emission tomography. JAMA Neurol 71, 1282-1289.

[85] Toombs J, Paterson RW, Lunn MP, Nicholas JM, Fox NC, Chapman MD, Schott JM, Zetterberg H (2013) Identification of an important potential confound in CSF AD studies: Aliquot volume. Clin Chem Lab Med 51, 2311-2317.

[86] García Barrado L, Coart E, Vanderstichele HMJ, Burzykowski T (2015) Transferring cut-off values between assays for cerebrospinal fluid Alzheimer's disease biomarkers. J Alzheimers Dis 49, 187-199.

[87] CDISC Vision \& Mission http://www.cdisc.org/system/ files/all/CDISC-4-Pager_pages_web.pdf, Accessed May 11, 2016.

[88] Bittner T, Zetterberg $\mathrm{H}$, Teunissen CE, Ostlund RE, Militello M, Andreasson U, Hubeek I, Gibson D, Chu DC, Eichenlaub U, Heiss P, Kobold U, Leinenbach A, Madin K, Manuilova E, Rabe C, Blennow K (2016) Technical performance of a novel, fully automated electrochemiluminescence immunoassay for the quantitation of $\beta$-amyloid
(1-42) in human cerebrospinal fluid. Alzheimers Dement 12, 517-526.

[89] Lasser R, Ostrowitzki S, Scheltens P, Boada M, Dubois B, Dorflinger E, Balas B, Nikolcheva T, Volz D, Ashford E, Edgar C, Garibaldi G, Fontoura P, Santarelli L (2015) Efficacy and safety of gantenerumab in prodromal AD: Results from Scarlet Road-a global, multicenter trial. Alzheimers Dement 11(Suppl), P331-P332.

[90] Rifai N, Watson ID, Miller WG (2012) Commercial immunoassays in biomarkers studies: Researchers beware! Clin Chem 58, 1387-1388.

[91] McGhee DJM, Ritchie CW, Thompson PA, Wright DE, Zajicek JP, Counsell CE (2014) A systematic review of biomarkers for disease progression in Alzheimer's disease. PloS One 9, e88854.

[92] Khan MU, Bowsher RR, Cameron M, Devanarayan V, Keller S, King L, Lee J, Morimoto A, Rhyne P, Stephen L, Wu Y, Wyant T, Lachno DR (2015) Recommendations for adaptation and validation of commercial kits for biomarker quantification in drug development. Bioanalysis 7, 229-242. 